\title{
Barriers and facilitators in accessing dementia care by ethnic minority groups: a meta-synthesis of qualitative studies
}

\author{
Cassandra Kenning ${ }^{*}$ D, Gavin Daker-White, Amy Blakemore, Maria Panagioti and Waquas Waheed
}

\begin{abstract}
Background: It is estimated that there are about 25,000 people from UK ethnic minority groups with dementia. It is clear that there is an increasing need to improve access to dementia services for all ethnic groups to ensure that everyone has access to the same potential health benefits. The aim was to systematically review qualitative studies and to perform a meta-synthesis around barriers and facilitators to accessing care for dementia in ethnic minorities.

Methods: Databases were searched to capture studies on barriers and facilitators to accessing care for dementia in ethnic minorities. Analysis followed the guidelines for meta-ethnography. All interpretations of data as presented by the authors of the included papers were extracted and grouped into new themes.
\end{abstract}

Results: Six hundred and eighty four papers were identified and screened. Twenty eight studies were included in the meta-synthesis. The analysis developed a number of themes and these were incorporated into two overarching themes: 'inadequacies' and 'cultural habitus'.

Conclusions: The two overarching themes lend themselves to interventions at a service level and a community level which need to happen in synergy.

Trial registration: The review was registered with PROSPERO: CRD42016049326.

Keywords: Dementia, Barriers, Facilitators, Access, Review, Meta-ethnography, Ethnicity, Minority

\section{Background}

A study looking at global prevalence of dementia has suggested that age-specific prevalence of dementia varies little between world regions [1]. Ethnic minorities comprise approximately $34 \%$ of the population in the US [2], and $14 \%$ of the total population in the UK [3]. Currently, it is estimated that there are about 25,000 people from UK ethnic minority groups with dementia but these figures are thought to be underestimated [3]. In the UK, this means one person in every $88(1.1 \%)$ of the entire UK population having some form of dementia, costing the UK economy $£ 23$ billion per year. As a result the cost of dementia to the economy is greater than that for heart disease and cancer combined [4]. Incidence has

\footnotetext{
* Correspondence: Cassandra.kenning@manchester.ac.uk Division of Population Health, Health Services Research and Primary Care, School of Health Sciences, The University of Manchester, 5th floor, Williamson Building, Oxford Road, Manchester M13 9PL, UK
}

been forecast to increase by $38 \%$ over the next 15 years and $154 \%$ over the next 45 years [5].

However, there may also be some evidence that rates of dementia are decreasing in some high-income countries. A recent study comparing prevalence of dementia in the US between 2000 and 2012 suggests that prevalence of dementia has actually declined significantly in this period [6]. Similarly in the UK a $20 \%$ drop in the overall dementia incidence rate from 1991 to 2015 was reported [7]. Dementia remains a global problem which represents major emotional and financial burden for patients, relatives and health authorities.

It is clear that there is an increasing need to improve access to dementia services for all ethnic groups to ensure that everyone has access to the same potential health benefits [8]. Many characteristics are common to ethnic populations, for example, South Asians represent a large diverse group where accurate assessment of dementia and access to appropriate care is challenging due 
to low English literacy, small number of therapists with clinical skills, lack of recognition and costs to cover provision of extra resources like transport and interpreters $[8,9]$.

There is a growing body of evidence for the need to intervene to improve help-seeking and promote early diagnosis of dementia in minority ethnic groups [8-10]. Many countries are now carrying out educational campaigns around dementia [8]. However, there are as yet no published RCTs that show if outreach with these groups improves help-seeking and early diagnosis. Past research and reviews have only focused on bringing together barriers and facilitators as themes. However, there is a need to understand the relationships between these themes with an aim to align them with future intervention approaches and implementation studies.

As a step in this direction we propose meta-synthesis to assist knowledge synthesis through a process of reconceptualisation of themes across included qualitative studies [11]. During the meta synthesis, the interpretations and explanations in the included studies undergo a process of deconstruction, translation and reconstruction as 'a means to grasp the particulars within the wholes' [12]. The evolving explanatory framework can then be applied to the specific aims of this review to understand barriers and facilitators to accessing dementia care by ethnic minority groups. To our knowledge this has not been done previously.

This systematic review and meta-synthesis aims to systematically explore views and experiences of ethnic minority patients, carers and health professionals on barriers and facilitators in accessing dementia care, with the purpose of discussing how such findings could contribute to the design of efficient interventions to improve access to dementia care for ethnic minority groups.

\section{Methods}

Literature search

The following electronic databases were searched: Cochrane Central Register of Controlled Trials (CENTRAL) 31March 2016, MEDLINE (Ovid) from inception to 3 April 2016, PsycINFO (Ovid) from inception to 3 April 2016, Embase (Ovid) from inception to 4 April2016, Cochrane Database of Systematic Reviews 2005 to 4 April 2016. In addition we reviewed reference lists of included studies and systematic reviews to identify any relevant papers not identified in the original search.

Searches were conducted to specifically capture studies on barriers and facilitators in accessing care for dementia in ethnic minorities. Search terms included: dementia, Alzheimer's Disease; ethnic*, Asian, Black, African, minority. Searches using these terms identified around 6500 papers. To further limit the search we introduced criteria specifying qualitative research. These included: qualitative, interview, focus group*, content analysis, discourse, grounded theory, ethnograph*.

The search is available in Additional file 1.

\section{Eligibility criteria}

Studies were eligible for inclusion in this review if they met the following criteria:

Population: Ethnic minority patients with dementia or memory problems; carers of ethnic minority patients with dementia; health professionals working with ethnic minority patients.

Outcomes: The qualitative analysis described barriers and enablers to ethnic minority patients accessing dementia care, or carers and health professionals' views of barriers in accessing dementia care.

Setting/context: Any country without restriction in publication date and language.

Study design: Empirical studies published as peer-reviewed journal articles or conference papers which report qualitative methods of data collection and analysis. An operational definition of this criterion was that studies used semi-structured interview data and content analysis reports were included in this classification. Mixed method studies were eligible if the qualitative data were analysed separately to the quantitative data. Unpublished dissertations and book chapters were excluded.

\section{Study selection and data extraction}

Titles and abstracts were screened by author (CK) and full papers of potentially relevant abstracts were obtained. A second researcher cross-checked and agreed the included and excluded papers (MP), final decisions about inclusion were made by the CI (WWW) if there was no consensus.

Data were extracted by the author (CK) onto a standardised Excel spreadsheet. Data was collected on study details including context and participants, design and methods, as well as author's interpretations of their data. A 50\% sample of the papers were double extracted by two independent reviewers to ensure reliability of the data extraction.

\section{Critical appraisal of study quality}

Two independent reviewers appraised the identified studies using a checklist adapted from the Critical Appraisal Skills Programme (CASP) qualitative checklist [13]. We did not exclude papers based on quality.

\section{Translation and synthesis}

Analysis followed the guidelines for meta-ethnography outlined by Noblit and Hare [11]. Three order constructs were generated. First order constructs are defined as direct 
participant quotes reported in the papers. Second order constructs are defined as the authors' interpretations of participants' quotes expressed as themes, extracted from both the results and discussion sections of papers in order to capture all constructs. Third order constructs refer to synthesised constructs that emerge from the analysis of first and second order constructs [13]. Papers were read and re-read by two reviewers and first and second order constructs were extracted and managed using Microsoft Excel. Reviewers (CK, GDW, AB) independently sifted the second order constructs, and group discussions were held to compile new third order constructs that summarised and encompassed the various themes across study findings.

For analysis, all interpretations of data presented by the authors of the included papers were extracted. The aim was to see how previous authors had interpreted and presented the results of their studies. Authors comments that interpreted their data were extracted in to an excel spread sheet. The extracted data were then grouped into themes independently by two further reviewers (GDW, AB). Their groupings were then compared and discussed by the team to ensure consensus. Once the themes had been broadly agreed the first author read through the data in each of the themes checking that the interpretation of the data was correct and suggesting changes based on the original context of the studies. The data was read and re-read to develop new concepts which incorporated the different interpretations of the themes.

The results are reported as per PRISMA guidelines for systematic reviews.

\section{Results}

\section{Search results}

Figure 1 shows the processes of selection. The initial search identified 999 records with a further 15 identified from reference list searches. After duplicates were removed, 684 records remained and the titles and abstracts were read to identify relevant papers. Six hundred and twenty nine records were excluded at this stage and 55 papers were selected and fully screened to establish if the inclusion criteria were met. Two further papers were excluded at the data extraction phase due to lack of useable data. In total 28 papers were included in the review (Table 1).

\section{Quality assessments}

An $a$ priori decision was made that every paper meeting the inclusion criteria would be included in the review. While quality is an important consideration for experimental studies, application of quality criteria to qualitative research has been widely debated [13]. Rather than identifying poor research methodology, assessment tends to identify areas of inadequacy in reporting.

The papers were assessed for quality and we found that most were generally of good quality. However, there were areas where reporting was often poor. These areas were in clearly describing the role of the researcher, and in describing the sampling methodology, as shown in Table 2 below.

Authors of the papers which did not report data required for the quality assessment were not contacted to try and obtain the information. This decision was made because we were not excluding papers based on quality and the details were not required for the analysis we were conducting.

\section{Barriers to service use by ethnic minorities}

The original themes presented by the authors of the papers were grouped and reinterpreted to develop a number of new concepts around barriers to accessing dementia care (available in Additional file 2). Further consideration and discussion by the authors divided the new concepts into two new overarching concepts: inadequacies and cultural habitus/experience (Table 3).

Inadequacies The first overarching concept was of inadequacies, this incorporated all of the original themes around deficits in education and service provision. It was often reported $(n=19)$ that both general community members and carers for people with dementia felt that they did not have the necessary information about dementia - its causes, its symptoms and prognosis.

"they had little knowledge of the condition of dementia or how quality of life might be improved". \#6, pp388

"Families described their own misperceptions and lack of understanding about the nature of dementia as the main barriers to early diagnosis". \#11, pp165

Many of the studies also reported that the lack of knowledge of the disease and of its causes and symptoms, led in many cases to normalisation of dementia as part of getting older. Linked to this concept were preconceived ideas on the treatability of dementia with many reporting that as family carers did not view dementia as a disease it was therefore not treatable and so the perceived need to seek medical intervention was absent.

"families assumed that the dementia symptoms were natural for an older person and, thus, denied the need to seek medical attention or other resources". \#5, pp118

"None of the participants viewed mind loss as a reason to seek health care". \#13, pp7

"it was not clear to them why going to a doctor would be helpful, calling it "a waste of time," stating, "the doctor can't do much to bring my father's memory back", or they attributed the changes to normal aging, "my mother is old. "” \#19, pp8 


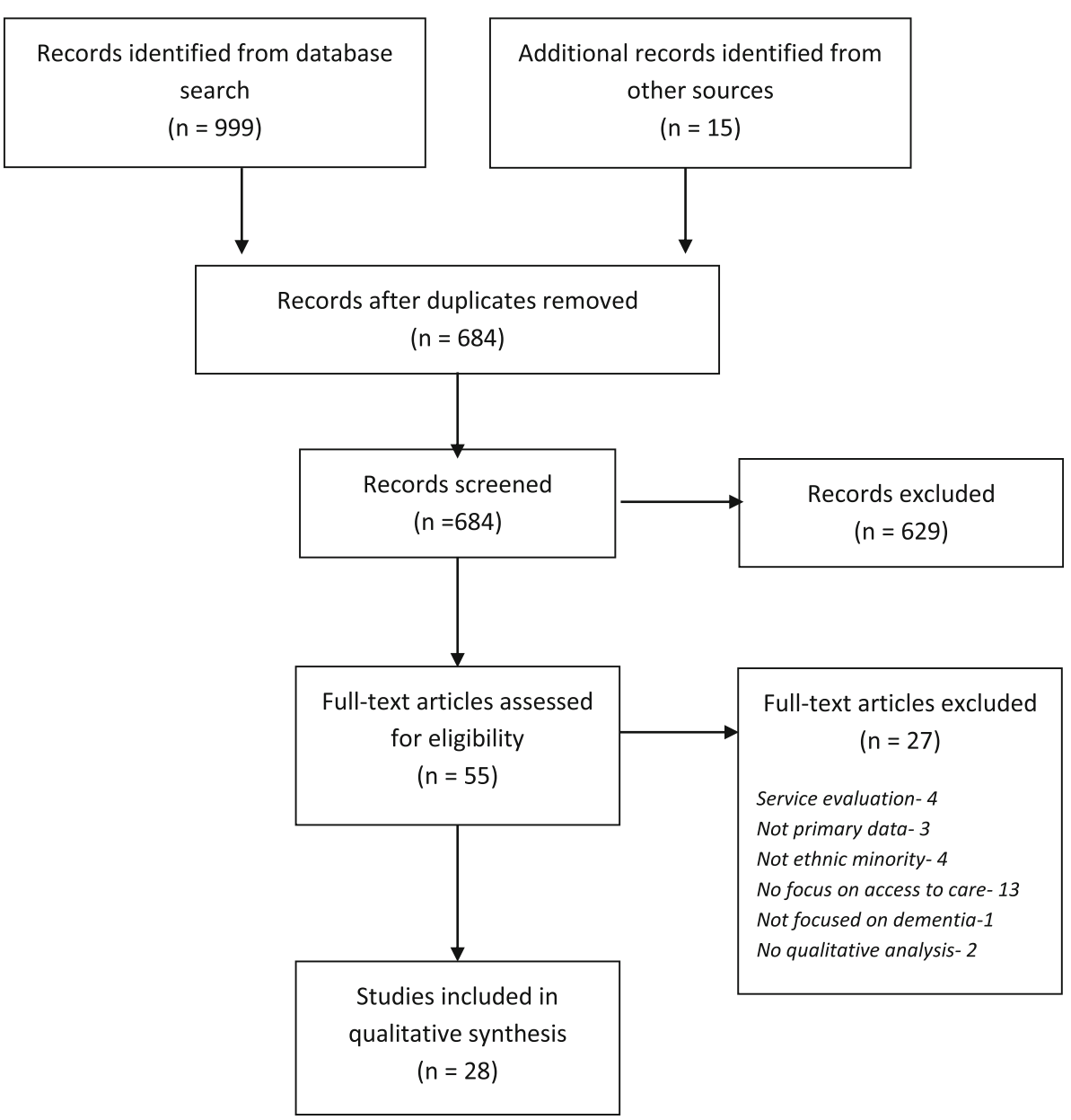

Fig. 1 PRISMA diagram

As well as lack of knowledge about the disease, many papers $(n=12)$ also reported a lack of knowledge, familiarity and awareness of services available to dementia patients. This was further compounded by an inability to successfully navigate the system with language barriers being cited as a major obstacle to accessing relevant information.

"reflected that they had been bewildered about the availability of services and how they could be accessed". \#18, pp244

"The biggest concern expressed by participants was that mainstream dementia services did not often have bilingual staff". \#24, pp5

The lack of knowledge was not limited to carers or the community but also within the health care system. Several studies $(n=9)$ reported on the lack of specialist dementia knowledge, particularly among GPs. In many cases the attitudes of GPs were seen to reinforce normalisation of memory loss as part of ageing, resulting in minimisation of carer concerns and failure to reach diagnosis.

"that GP time was limited and GPs would prioritise severe dementia and physical illnesses and dismiss memory problems as being due to old age". \#30, pp5

"newly knowledgeable family members encountered medical providers who were less well informed about dementia. Lack of specialized knowledge on the part of medical providers in some cases interfered with initial diagnosis" \#11.pp166

There were also a number of other inadequacies in the healthcare system that were highlighted by the studies, such as service limitations $(n=7)$. Those that did, reported on the lack of choice carers and patients face when seeking formal support services. Services often lacked cultural awareness and diversity for interacting with different cultural communities. Those services that did cater to the needs of minority patients were 


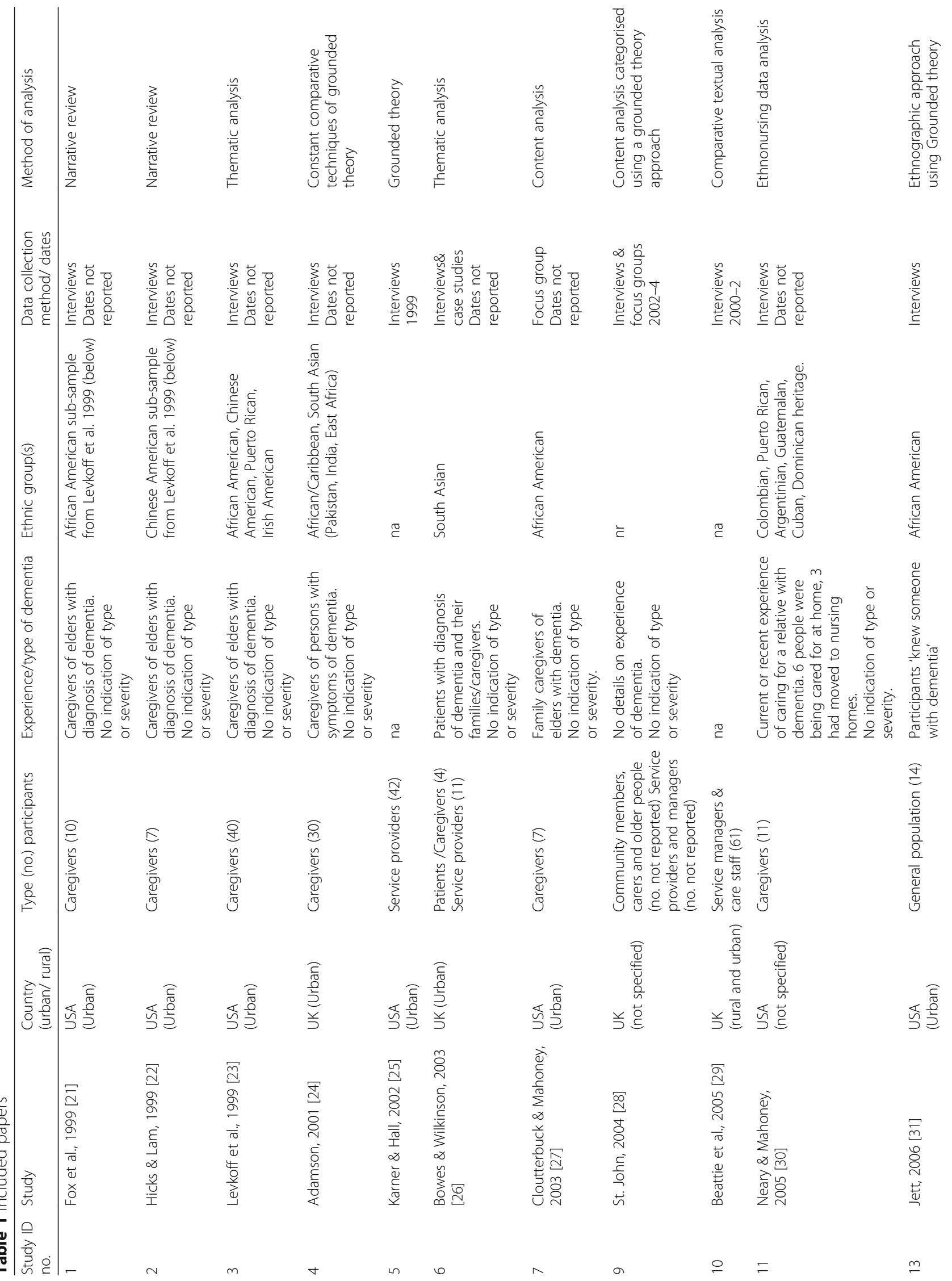



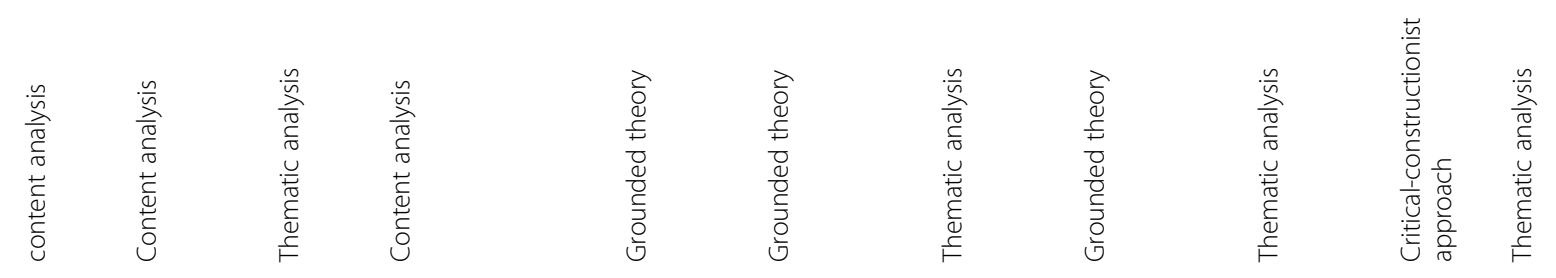

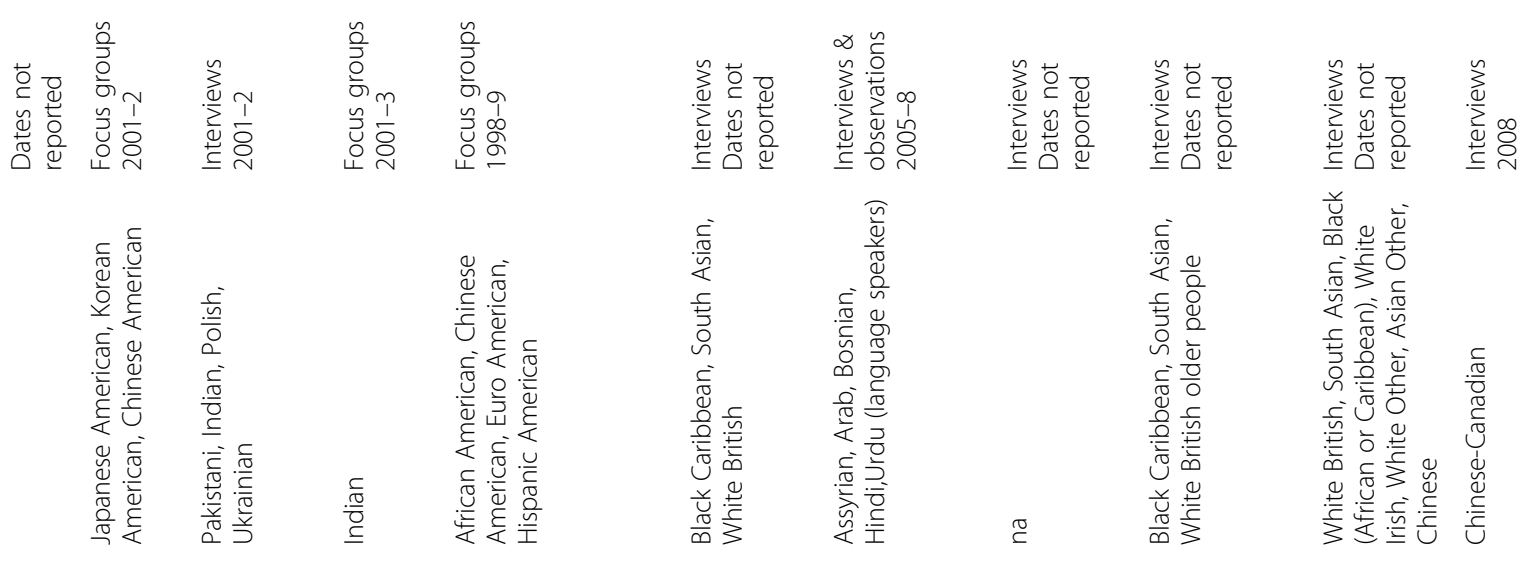

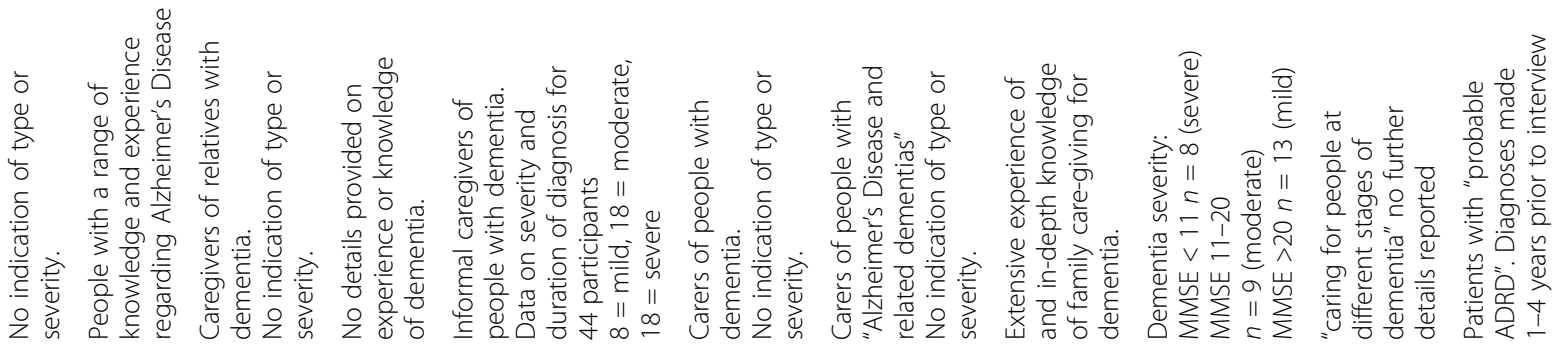

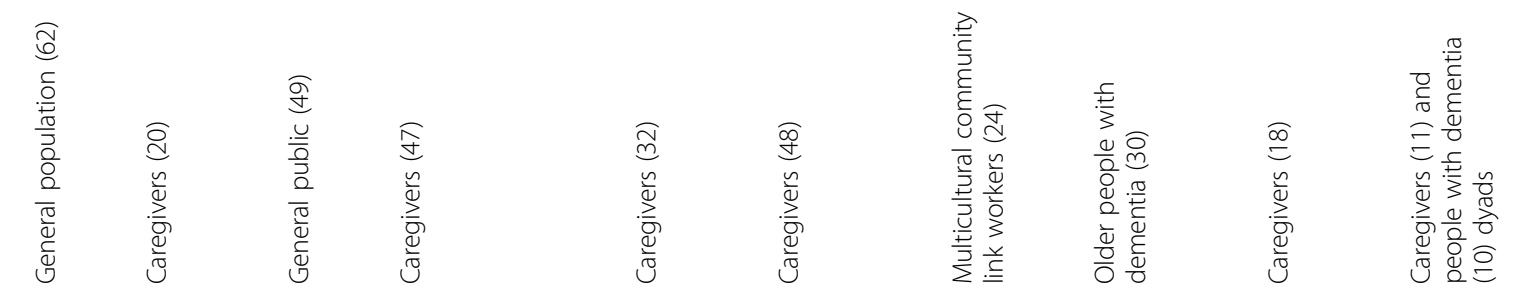

\begin{tabular}{|c|c|c|c|c|c|c|c|c|c|}
\hline 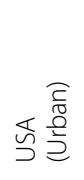 & 方产 & 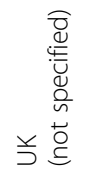 & 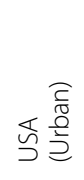 & 方穷 & 宽 & 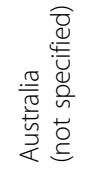 & 竞 & 竞 & 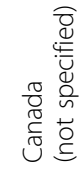 \\
\hline 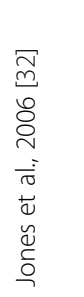 & 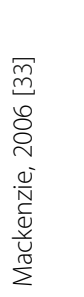 & 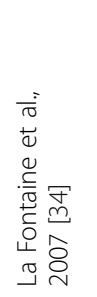 & 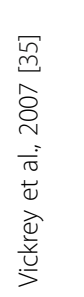 & 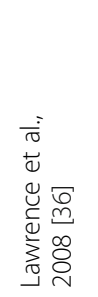 & 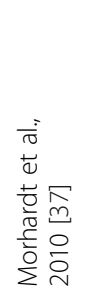 & 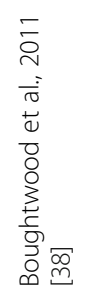 & 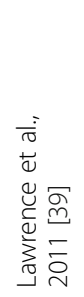 & 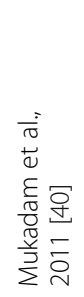 & 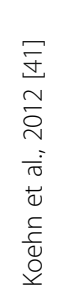 \\
\hline$\Xi$ & $\stackrel{n}{\sim}$ & $\underline{\varphi}$ & $\approx$ & $\stackrel{\infty}{\infty}$ & $\stackrel{\rho}{ }$ & 이 & $\bar{\sim}$ & $\approx$ & $\ddot{\sim}$ \\
\hline
\end{tabular}




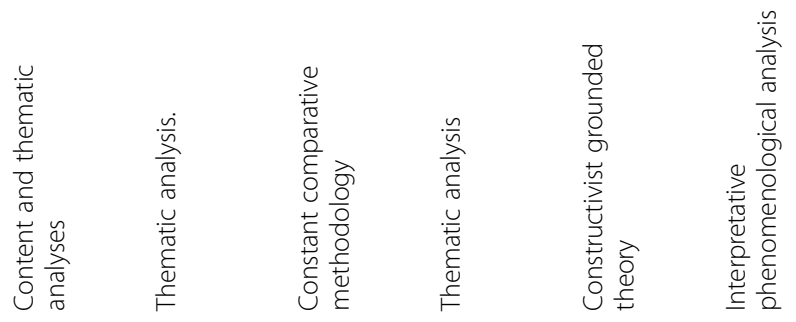

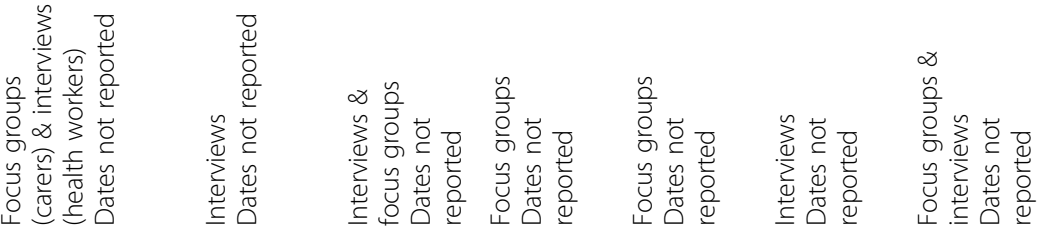

需

$\frac{\sqrt{2}}{\frac{\pi}{5}}$

高

高

离

U 峞

西

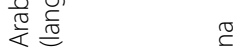

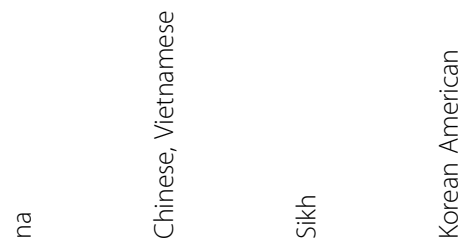

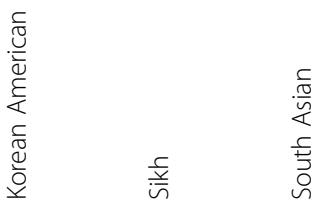

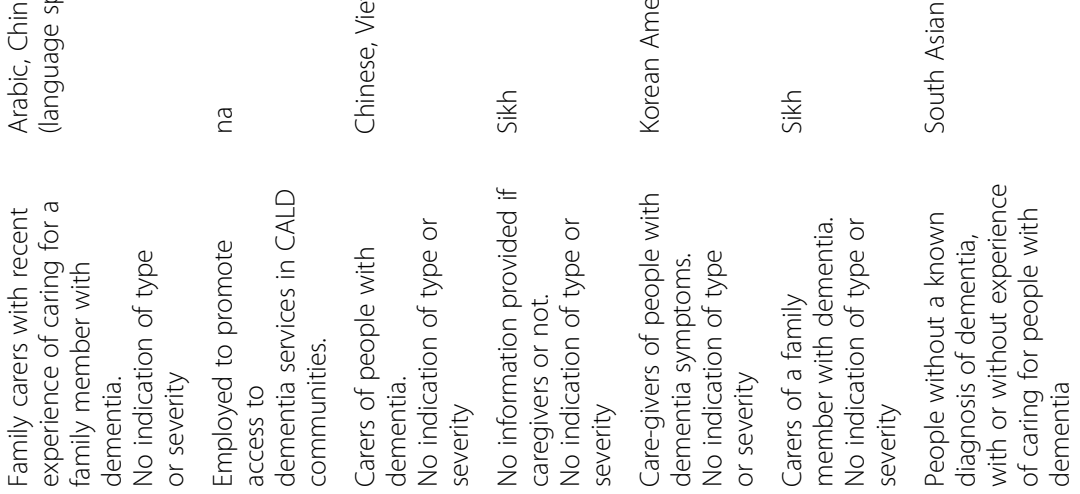

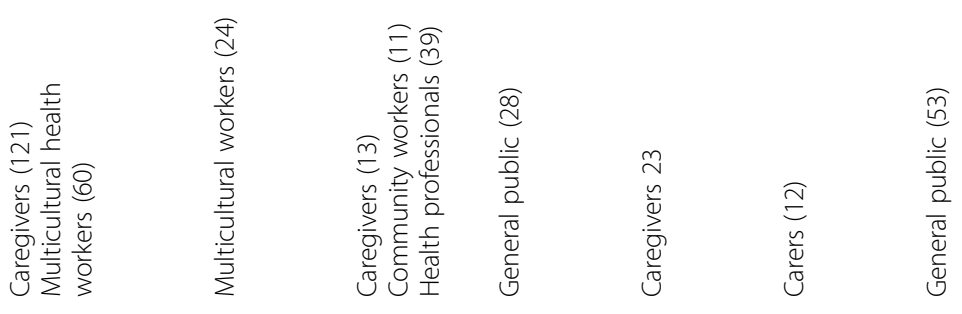

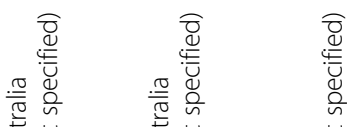

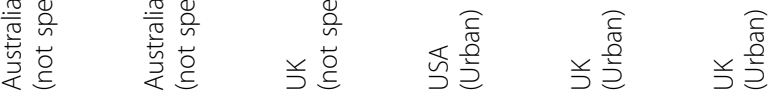

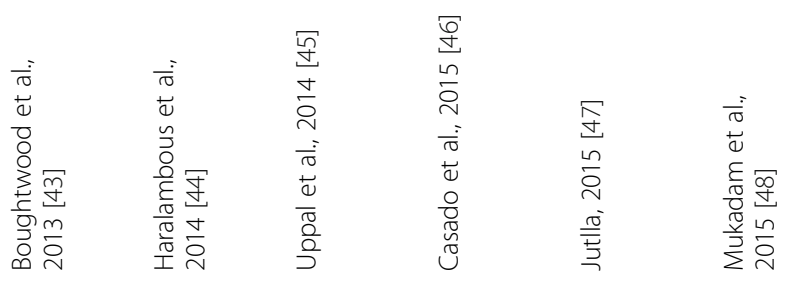

$\stackrel{๗}{\sim} \quad \triangleq$

$\lesssim \quad \stackrel{\sim}{\sim}$

$\stackrel{\infty}{\cap}$

๙

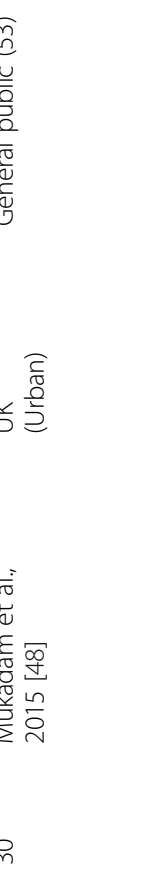


Table 2 Quality criteria and results

\begin{tabular}{|c|c|c|c|}
\hline Question & Yes & No & Unclear \\
\hline Is this study qualitative research? & 28 & 0 & 0 \\
\hline Are the research questions clearly stated? & 28 & 0 & 0 \\
\hline Is the qualitative approach clearly justified? & 24 & 4 & 0 \\
\hline Is the approach appropriate for the research question? & 24 & 0 & 4 \\
\hline Is the study context clearly described? & 28 & 0 & 0 \\
\hline Is the role of the researcher clearly described? & 13 & 15 & 0 \\
\hline Is the sampling method clearly described? & 14 & 14 & 0 \\
\hline Is the sampling strategy appropriate for the research question? & 14 & 0 & 14 \\
\hline Is the method of data collection clearly described? & 25 & 2 & 1 \\
\hline Is the data collection method appropriate to the research question? & 25 & 0 & 3 \\
\hline Is the method of analysis clearly described? & 22 & 4 & 2 \\
\hline Is the analysis appropriate for the research question? & 23 & 0 & 5 \\
\hline Are the claims made supported by sufficient evidence? & 28 & 0 & 0 \\
\hline
\end{tabular}

often geographically widely dispersed with long waiting lists, resulting in poor accessibility for carers and patients.

"The main problems identified with ethno-specific services were the long waiting lists due to the high demand, the observation that staff were not always well trained in dementia and that some staff did not speak the language of the community that the service was catering to". \#24, pp5
"Some participants also felt that services needed to have a better understanding of cultural needs and the lack of it led to worse outcomes". \#30, pp5

"general shortage of dementia services across the region, never mind the dearth of specialist provision for marginalised groups". \#10, pp71

Cultural habitus Cultural habitus was a concept devised by Bourdieu to refer to socialised norms or tendencies

Table 3 Barriers and facilitators

\begin{tabular}{|c|c|c|}
\hline \multirow[b]{2}{*}{ Overarching concept } & BARRIERS & FACILITATORS \\
\hline & New concept & New concept \\
\hline \multirow{4}{*}{ Inadequacies } & $\begin{array}{l}\text { Lack of carer/patient understanding of the causes and symptoms } \\
\text { of dementia }\end{array}$ & \multirow[t]{2}{*}{ Improving knowledge of dementia } \\
\hline & $\begin{array}{l}\text { Lack of Knowledge, familiarity and awareness of services and how } \\
\text { to navigate the system }\end{array}$ & \\
\hline & $\begin{array}{l}\text { Professionals lack of specialist knowledge and lack of cultural and } \\
\text { linguistic ability to achieve diagnosis }\end{array}$ & $\begin{array}{l}\text { Improving training for professionals in } \\
\text { identifying and screening for dementia }\end{array}$ \\
\hline & Limitations of available services and lack of cultural awareness & $\begin{array}{l}\text { Broadening and adapting services } \\
\text { Continuity of care }\end{array}$ \\
\hline \multirow{8}{*}{ Cultural habitus/experiences } & Preconceived ideas of treatability /normalisation & \\
\hline & $\begin{array}{l}\text { Anxiety/trust issues about 'outside' support and its cultural } \\
\text { appropriateness }\end{array}$ & \multirow[t]{2}{*}{ Tackling the issue of 'outsiders' } \\
\hline & Issues around trust and racism, both historic and current & \\
\hline & $\begin{array}{l}\text { Societal stigma of mental illness and denial or concealment as a } \\
\text { defence against the reactions of others }\end{array}$ & \multirow[t]{5}{*}{$\begin{array}{l}\text { Addressing societal stigma/denial/ } \\
\text { concealment }\end{array}$} \\
\hline & $\begin{array}{l}\text { Cultural issues impacting on perceptions of Western medicine } \\
\text { and the acceptability of services }\end{array}$ & \\
\hline & $\begin{array}{l}\text { The impact of cultural/familial expectations and community } \\
\text { perceptions on care decisions }\end{array}$ & \\
\hline & $\begin{array}{l}\text { Health care provider exclusion and dismissal of carer concerns/ } \\
\text { Negative carer experiences of help seeking }\end{array}$ & \\
\hline & Negative emotions associated with response from own community & \\
\hline
\end{tabular}


that guide behaviour and thinking. It describes the deeply ingrained habits, skills, and dispositions people exhibit as a result of life experience [14]. Cultural issues were often seen to play a major role in families seeking help with dementia patients.

Many of the barriers to accessing care described in the papers reflected the strong impact of cultural norms within ethnic minority groups. This was seen to have a huge impact on care decisions and perceptions of Western medicine and service access.

"They also share a pervasive mistrust of government assistance and the medical system". \#5, pp117

"Families often reported that the structure and rules of professional caregiving systems impacted significantly on their care decisions". \#2, pp443

Stigma around mental health and dementia was a fairly consistent theme, evident in many of the studies $(n=13)$. As a result of community responses carers and family members displayed feelings of guilt, denial, fear, embarrassment and shame. Denial and concealment of the condition was evident as a result of the associated stigma.

"The presence of a very high degree of stigma associated with it, and with other mental health problems, was revealed, contributing to the reluctance to acknowledge symptoms and get help" \#9, pp23

"Shame and stigma are among the most difficult barriers to surmount for many Asian families". \#14, pp20

"Families commonly responded with denial, fear, and embarrassment when their elders exhibited dementia symptoms".\#5, pp118

Of particular importance was the concept of 'outsiders' often related to issues of trust and perceptions of racism. Many authors $(n=11)$ reported that interviewees expressed anxiety and reluctance about letting other people come into the home to provide care or support. There is little choice within the health and social care systems and so matching professional carers by language, religion or gender is rare and hard to achieve. This results in care options that are considered unacceptable particularly to certain communities.

"Arabic communities struggled with having an outsider come into the home and some Arabic family carers stated that personal care, even by someone of the same gender, was unacceptable". \#24, pp6

"When health care was received it had not been found acceptable and fears of racism were expressed". \#13, pp8

Community expectations were reported in 10 papers as a barrier to formal services and were seen to put increased pressure on family members as clearly defined responsibilities and obligations to the family were enforced. Such traditions and beliefs are not easily addressed. Cultural impacts were further reinforced by perceptions of institutionalised racism and negative carer experiences of help seeking resulting in further issues around trust in the health and social care systems. Beliefs around western medicine were also identified as a barrier as some authors $(n=9)$ reported strongly held folk beliefs around health, ageing dementia.

"expressed similar notions of having 'no choice' but to cope with their carer role which, for them, was due to the expectation to cope with situations of stress and adversity from older members within the Sikh community". \#29, pp1047"

"Believing in curses, punishment, and possession led individuals to seek non-medical cures". \#5, pp123

"perception of negative health care provider attitudes and behavior encountered during the process of obtaining a diagnosis". \#7, pp227

\section{Facilitators to service use by ethnic minorities}

Few of the papers in this review focussed on facilitators to service use. In fact only four papers focussed on it in a meaningful way $(5,6,24,25)$. As a result there was much less information on facilitators available. Most of the reported facilitators mapped on to service level interventions, so educating patients and carers about dementia, improving screening and recognition of dementia by GPs, and broadening and adapting services to meet specific population needs were seen as key.

"The importance of a sympathetic GP and continuity of care from a professional were also emphasized". \#22, pp1075

"a need to develop awareness of and knowledge about dementia, and to promote more culturally sensitive practice among health and social care professionals". \#6, pp391

"Bilingual workers from ethno-specific or multicultural agencies could provide a personal and tailored service 
because they had an understanding of the language and culture of the clients and their families". \#24,pp5"

"When planning meals and program activities, services need to provide a range of options that reflect the cultural diversity of service users". \#24, pp8

There was some discussion of cultural issues but there was very limited information presented as to what might reduce the impact on help seeking and accessing care services. The only concepts covered were addressing societal stigma/denial/concealment, mainly through education and outreach within the community; and working with the community to build trust and confidence in care providers.

"outreach materials and interactions needed to be culturally sensitive and tailored to the targeted population". \#5, pp121

"Presenting dementia as a medical condition was widely favoured ...the use of a physical illness idiom could help move people towards a more appropriate social model of dementia, without stigma or 'supernatural' connotations". \#6, pp392

"normalising help-seeking and breaking down the stigma associated with both the symptoms and help-seeking might encourage earlier help-seeking”. \#30, pp6

"Providers found it helpful to offer traditional food, and to celebrate national holidays of their clients' home countries. Additionally, providers developed service activities around social themes in noninstitutional settings. Support groups were referred to as "clubs" or "tea-time." “\#5, pp126

\section{Discussion}

The review identified 28 qualitative papers around barriers and facilitators to dementia services by ethnic minority populations. We conducted a meta-synthesis that has not previously been undertaken, with the aim of better understanding the relationships between barriers and facilitators to align them with future intervention approaches.

Many of the papers included in the synthesis reported similar themes in terms of perceived barriers to dementia diagnosis and access to care. Whilst identifying these barriers is important, papers tended to focus on these as isolated themes within their study population. This meta synthesis brings together those studies to generate a new understanding of the existing research. Whilst different ethnic minority groups should not be considered as a single homogenous group, there are commonalities that result in reduced understanding of dementia and the importance of diagnosis and treatment.
We developed two overarching concepts from the literature: inadequacies and cultural habitus. We suggest that the two concepts lend themselves to interventions at either a service level (inadequacies) or a community level (cultural habitus). There was a paucity of research focussed on facilitating factors and most of that research reflected on service level facilitators. To achieve a more sustainable approach to facilitating access to services there is an argument that it is as important to educate ethnic minority communities about how health professionals and health services work as it is vice versa [15].

Inadequacies tended to be linked to service level barriers mainly focussing on the need for education that is inclusive of and directly related to the target population. To tailor the literature and education, simply translating generic versions of patient information is not adequate [16]. There is a need for redesign of the literature making it socially and culturally appropriate, for example, by featuring pictures and case examples from the relevant community.

Dissemination of information is also important. Research suggests current approaches may not have enough penetration into the ethnic groups. Alternates via community organisations, media or community champions, needs to be further explored [17].

Diagnosis of dementia in ethnic minority populations remains problematic due in part to the diagnostic tools and skills of primary care staff and in part to cultural beliefs. As Primary care is often the initial point for recognition and diagnosis of dementia, this is a key area for further research. Diagnosis opens the doorway to access to services and also serves to identify who the patient's primary carers are and what support they need.

There is an assumption that ethnic minority populations prefer to 'care for their own', and whilst the literature supports this to some degree, this should not be relied on as an alternative to formal support and intervention [18]. The literature also shows that as in other cultures the burden placed on family members is great and there often comes a point where it is not possible to give a patient the care they need without professional and formal care arrangements.

Many of the papers focussed on the need for service level interventions, tailoring services to specific ethnic groups. One reason for this may be that it may be an easier area to address than trying to impact changes at a cultural level within target populations. With increased resources and suitable adaptations to processes such as information provision, training for health professionals and culturally adapting services to specific needs of a population, many of these barriers could be addressed, but it would come at significant cost to the health service [19].

There was also some focus on cultural engagement and whilst interacting with the minority communities may help acceptance to some degree, it may not result in substantial 
changes in beliefs and behaviour. Aspects of cultural habitus can be both overt and covert in nature (people are generally not aware of how it impacts on them), even with investment in services they may not be amenable to change or it would likely be part of a long process which requires years of intervention to produce small changes.

The two concepts of inadequacies and cultural habitus are strongly linked and in no way independent of each other therefore, to address them separately is unlikely to produce desired results. This has also been explored in other areas such as the AMP model aimed at improving access to psychosocial interventions for common mental health problems [20]. Intervention at a service level, working to improve knowledge of dementia in the population and improving practitioner recognition of the problem and adapting services to give patients more choice will not work if cultural beliefs/expectations are not also taken in to consideration [20]. Our findings suggest that service level interventions could benefit by take place within community based interventions (Fig. 2).

Without parallel interventions a decision is needed about priorities for implementing interventions to improve care for ethnic minority groups. Is it better a) to spend time and resources on culturally adapting services, when without community based intervention, those services are unlikely to be utilised? Or b) first implementing an intervention at a community level, improving understanding and hopefully acceptance of services, but not having suitable adapted services to refer that community to?

The former would create a service which has no customers, and the latter would increase the need for services but would not be able to provide suitably adapted services.

\section{Future direction}

Population and health statistics show that dementia is a key concern and issues around culture will not disappear as the current immigrant population ages as population movement continues. If the cultural preference is to care for their community member with dementia themselves, services need to be adapted to take this in to consideration but not to rely upon it. Ongoing monitoring and support of carers is also important.

We have suggested a model in which intervention should occur at both a service level and a community level at the same time. Further research is required, supported by the processes of implementation science to explore ways in which dual targeted interventions could be implemented in primary care.

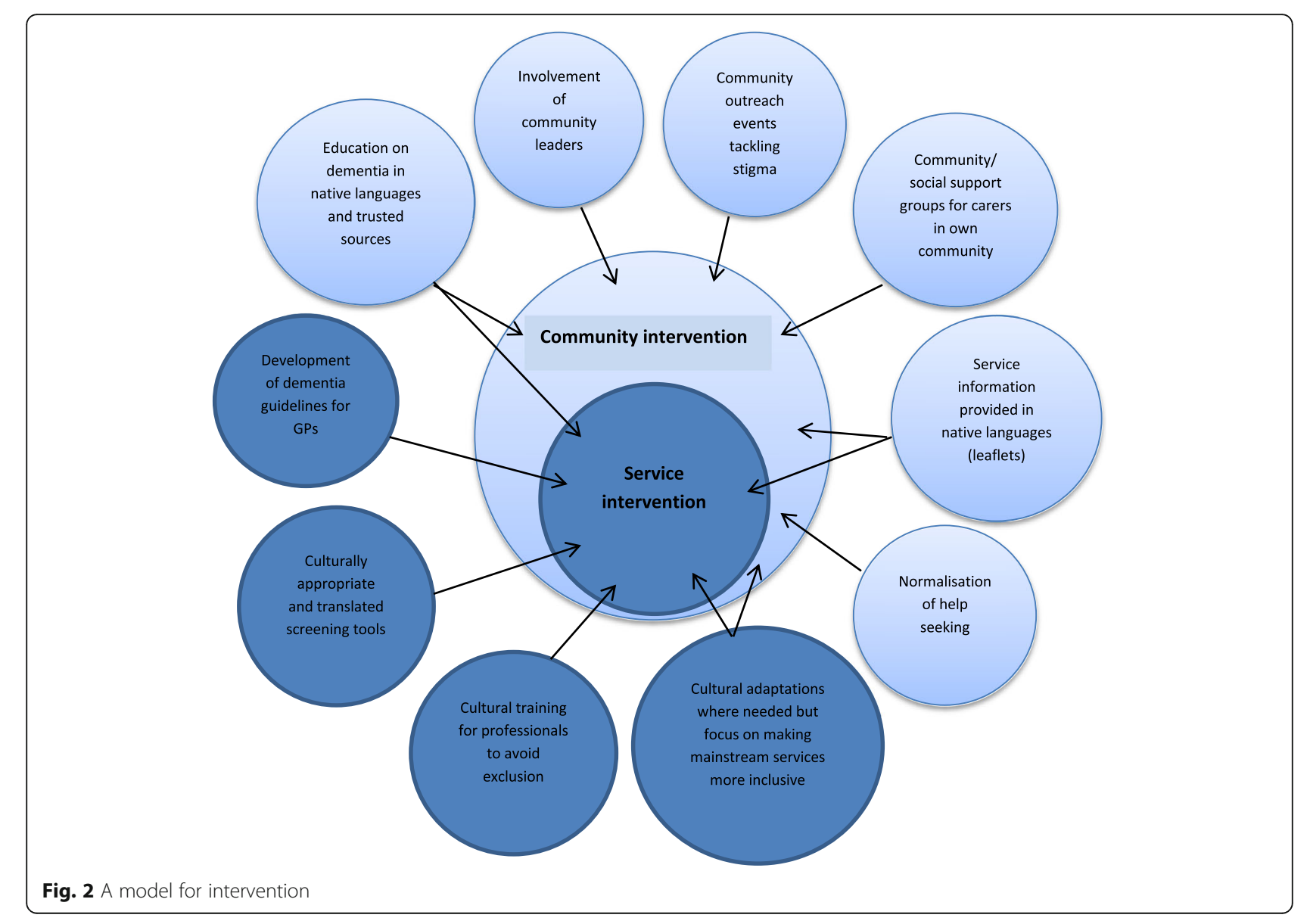




\section{Strengths and limitations}

The decision was made to focus on peer reviewed published work. Therefore we did not search the 'grey literature' for this review. Even though a systematic review of the literature was performed, it is possible that there are other studies that were not identified. This may be in part due to the lack of standardisation in terminologies used in this area. We focussed on papers that identified and reported on dementia and Alzheimer's Disease rather than 'memory problems' or 'memory loss' as there may be other causes for these conditions. However, we found 28 papers that fit our criteria, giving a large body of work for conducting a meta-ethnographic analysis. While papers had varying approaches and differing samples, there was evidence for data saturation across many themes.

Some of the themes raised are not necessarily specific to ethnic minority populations, for example, normalisation of dementia as part of ageing which can be seen in the general population. However, these themes and the suggested model for intervention still incorporate these barriers. The fact that some barriers are experienced by general populations does not detract from their relevance to ethnic minority groups.

We did not make a comparison of themes between ethnic minority populations or to general populations although this may provide a fruitful avenue for future research.

\section{Conclusions}

This review aimed to identify relevant papers that used qualitative methods to explore barriers and facilitators to accessing dementia care in ethnic minorities. The meta synthesis used a process of re-conceptualisation to further our understanding of barriers and facilitators across ethnic minority groups. Our results suggest that barriers should be addressed on two levels, service level interventions and personal or community level interventions, in conjunction to try and maximise their effectiveness. Further research in terms of the implementation of dual intervention strategies is needed.

\section{Additional files}

Additional file 1: Example search strategy for Ovid MEDLINE(R). Search strategy and search terms used to identify relevant studies. (DOCX $131 \mathrm{~kb}$ )

Additional file 2: Table showing the original themes around barriers extracted from papers with recoding to new concepts. Table showing the themes extracted from papers along with how they were ordered and recoded and how they were then grouped under new overarching concepts. (DOCX $20 \mathrm{~kb}$ )

\section{Acknowledgements}

Not applicable.

\section{Funding}

This project was funded by the National Institute for Health Research (NIHR) School for Primary Care Research (SPCR). Grant number SPCR 300. The funding body had no influence in the design of the study, collection, analysis, and interpretation of data and in writing the manuscript.

\section{Availability of data and materials}

The datasets used and/or analysed during the current study are available from the corresponding author on reasonable request.

\section{Authors' contributions}

All authors were involved in the design, analysis and interpretation of the data, and in revising the article for publication. All authors read and approved the final manuscript.

Ethics approval and consent to participate

Not applicable.

\section{Consent for publication}

Not applicable.

\section{Competing interests}

The authors declare that they have no competing interests.

\section{Publisher's Note}

Springer Nature remains neutral with regard to jurisdictional claims in published maps and institutional affiliations.

Received: 12 April 2017 Accepted: 22 August 2017

Published online: 30 August 2017

References

1. Prince M, Bryce R, Albanese E, Wimo A, Ribeiro W, Ferri CP. The global prevalence of dementia: a systematic review and metaanalysis. Alzheimers Dement. 2013;9(1):63-75.

2. US Census Bureau. Statistical abstract of the United States: 2012. Washington, DC: US Census Bureau; 2011. Report No.: 131st ed.

3. All Party Parliamentary Group on Dementia. Dementia does not discriminate: the experiences of Black, Asian and minority ethnic communities. London: Alzheimer's Society and the House of Commons All-Party Parliamentary Group (APPG) on Dementia, July 2nd; 2013.

4. Luengo-Fernandez R, Leal J, Gray A. Dementia 2010: the prevalence, economic cost and research funding compared with other major diseases: a report prepared by the health economics research Centre. Oxford: University of Oxford for the Alzheimer's Research Trust; 2010.

5. Travers T, Tunstall R, Whitehead C. Population Mobility and Service Provision: A report for London Councils. London: LSE; 2007.

6. Langa KM, Larson EB, Crimmins EM, Faul JD, Levine DA, Kabeto MU, et al. A comparison of the prevalence of dementia in the United States in 2000 and 2012. JAMA Intern Med. 2017;177(1):51-8.

7. Matthews FE, Arthur A, Barnes LE, Bond J, Jagger C, Robinson L, et al. A two-decade comparison of prevalence of dementia in individuals aged 65 years and older from three geographical areas of England: results of the cognitive function and ageing study I and II. Lancet. 2013;382:1405-12.

8. Mukadam N, Cooper C, Livingston G. Improving access to dementia services for people from minority ethnic groups. Curr Opin Psychiatry. 2013;26(4):409-14.

9. Mukadam N, Cooper C, Livingston G. A systematic review of ethnicity and pathways to care in dementia. Int J Geriatr Psychiatry. 2011;26(1):12-20.

10. Cooper C, Tandy AR, Balamurali TB, Livingston G. A systematic review and meta-analysis of ethnic differences in use of dementia treatment, care, and research. Am J Geriatr Psychiatry. 2010;18(3):193-203.

11. Noblit G, Hare R. Meta-ethnography: Synthesising qualitative studies. London: Sage; 1988

12. Thorne S, Jensen L, Kearney M, et al. Qualitative metasynthesis: reflections on methodological orientation and ideological agenda. Qual Health Res. 2004;14:1342-65.

13. Atkins S, Lewin S, Smith H, Engel M, Fretheim A, Volmink J. Conducting a meta-ethnography of qualitative literature: lessons learnt. BMC Med Res Methodol. 2008;8:21-30.

14. Bourdieu P. Pascalian Meditations. Stanford, California: Stanford University Press; 2000.

15. Badat OF. Ethnic minorities and mental health services: developing a more sustainable approach. Brit J Psychiat. 2010;196:265. 
16. Anderson LM, Scrimshaw SC, Fullilove MT, Fielding JE, Normand J. Culturally competent healthcare systems: a systematic review. Am J Prev Med. 2003. 24(3S):68-79.

17. Lamb J, Dowrick C, Burroughs H, Beatty S, Edwards S, Bristow K, et al. Community engagement in a complex intervention to improve access to primary mental health care for hard-to-reach groups. Health Expect. 2015; 18(6):2865-79

18. House of Commons All-Party Parliamentary Group on Dementia. Dementia does not discriminate: The experiences of black, Asian and minority ethnic communities. 2013.

19. Mier N, Ory MG, Toobert D, Smith ML, Osuna D, McKay J, et al. A qualitative case study examining intervention tailoring for minorities. Am J Health Behav. 2010;34(6):822-32.

20. Gask L, Bower P, Lamb J, Burroughs H, Chew-Graham C, Edwards S, AMP research group, et al. Improving access to psychosocial interventions for common mental health problems in the United Kingdom: narrative review and development of a conceptual model for complex interventions. BMC Health Serv Res. 2012;12:249.

21. Fox K, Hinton WL, Levkoff S. Take up the caregiver's burden: stories of care for urban African-American elders with dementia. Cult Med Psychiat. 1999; 23:501-29.

22. Hicks M, Lam M. Decision-making within the social course of dementia: accounts by Chinese-American caregivers. Cult Med Psychiat. 1999:23:415-52.

23. Levkoff S, LevyB WPF. The role of religion and ethnicity in the help seeking of family caregivers of elders with Alzheimer's disease and related disorders. J Cross Cult Gerontol. 1999:14:335-56.

24. Adamson J. Awareness and understanding of dementia in African/ Caribbean and south Asian families. Health and Social Care in the Community. 2001;9(6):391-6.

25. Karner TX, Hall LC. Successful strategies for serving diverse populations. Home Health Care Services Quarterly. 2002;21:107-31.

26. Bowes A, Wilkinson H. 'we didn't know it would get that bad': south Asian experiences of dementia and the service response. Health Soc Care Community. 2003:11(5):387-96.

27. Cloutterbuck J, Mahoney DF. African American dementia caregivers: the duality of respect. Dementia. 2003;2:221-43.

28. St. John T. Hidden Shame - A Review of the Needs of Asian Elders with Dementia and their Carers in a Kent Community. J Integrated Care. 2004;12:20-6.

29. Beattie A, Daker-White G, Gilliard J, Means R. 'they don't quite fit the way we organise our services'-results from a UK field study of marginalised groups and dementia care. Disability \& Society. 2005;20:67-80.

30. Neary SR, Mahoney DF. Dementia caregiving: the experiences of Hispanic/ Latino caregivers. J Transcult Nurs. 2005;16:163-70.

31. Jett KF. Mind-loss in the African American community: dementia as a normal part of aging. J Aging Stud. 2006;20:1-10.

32. Jones RS, Chow TW, Gatz M. Asian Americans and Alzheimer's disease: assimilation, culture, and beliefs. J Aging Stud. 2006;20:11-25.

33. Mackenzie J. Stigma and dementia east European and south Asian family carers negotiating stigma in the UK. Dementia. 2006;5:233-47.

34. La Fontaine J, Ahuja J, Bradbury NM, Phillips S, Oyebode JR. Understanding dementia amongst people in minority ethnic and cultural groups. J Adv Nurs. 2007;60(6):605-14.

35. Vickrey BG, Strickland TL, Fitten $\amalg$, Adams GR, Ortiz F, Hays RD. Ethnic variations in dementia caregiving experiences. J Hum Behav Soc Environ. 2007:15:233-49

36. Lawrence V, Murray J, Samsi K, Banerjee S. Attitudes and support needs of black Caribbean, south Asian and white British carers of people with dementia in the UK. Brit J Psych. 2008;193:240-6.

37. Morhardt $D$, Pereyra M, Iris M. Seeking a diagnosis for memory problems: the experiences of caregivers and families in five limited English proficiency communities. Alzheimer Dis Assoc Disord. 2010;24(Suppl):S42-8.

38. Boughtwood D, Shanley C, Adams J, Santalucia Y, Kyriazopoulos H, Pond D, Rowland J. Culturally and linguistically diverse (CALD) families dealing with dementia: an examination of the experiences and perceptions of multicultural community link workers. J Cross Cult Gerontol. 2011;26:365-77.

39. Lawrence V, Samsi K, Banerjee S, Morgan C, Murray J. Threat to valued elements of life: the experience of dementia across three ethnic groups. Gerontologist. 2011;51:39-50.

40. Mukadam N, Cooper C, Basit B, Livingston G. Why do ethnic elders present later to UK dementia services? A qualitative study. Int Psychogeriat. 2011;23:7,1070-7.
41. Koehn S, McCleary L, Garcia L, Spence M, Jarvis P, Drummond N. Understanding Chinese-Canadian pathways to a diagnosis of dementia through a critical-constructionist lens. J Aging Stud. 2012;26:44-54.

42. Shanley C, Boughtwood D, Adams J, Santalucia Y, Kyriazopoulos H, Pond D, Rowland J. A qualitative study into the use of formal services for dementia by carers from culturally and linguistically diverse (CALD) communities. BMC Health Serv Res. 2012;12:354.

43. Boughtwood D, Shanley C, Adams J, Santalucia Y, Kyriazopoulos H, Rowland J, Pond D. The role of the bilingual/bicultural worker in dementia education, support and care. Dementia. 2013;12(1):7-21.

44. Haralambous B, Dow B, Tinney J, Lin X, Blackberry I, Rayner V, Lee S-M, Vrantsidis F, Lautenschlager N, LoGiudice D. Help seeking in older Asian people with dementia in Melbourne: using the cultural exchange model to explore barriers and enablers. J Cross Cult Gerontol. 2014;29:69-86.

45. Uppal GK, Bonas S, Philpott H. Understanding and awareness of dementia in the Sikh community. Mental Health, Religion \& Culture. 2014;17:400-14.

46. Casado BL, Lee SE, Hong M, Hong S. The experience of family caregivers of older Korean Americans with dementia symptoms. Clin Gerontol. 2015;38:32-48.

47. Jutlla K. The impact of migration experiences and migration identities on the experiences of services and caring for a family member with dementia for Sikhs living in Wolverhampton, UK. Ageing Soc. 2015;35:1032-54.

48. Mukadam N, Waugh A, Cooper C, Livingston G. What would encourage help seeking for memory problems among UK-based south Asians? A qualitative study BMJ Open. 2015;5:e007990.

\section{Submit your next manuscript to BioMed Central and we will help you at every step:}

- We accept pre-submission inquiries

- Our selector tool helps you to find the most relevant journal

- We provide round the clock customer support

- Convenient online submission

- Thorough peer review

- Inclusion in PubMed and all major indexing services

- Maximum visibility for your research

Submit your manuscript at www.biomedcentral.com/submit
) Biomed Central 